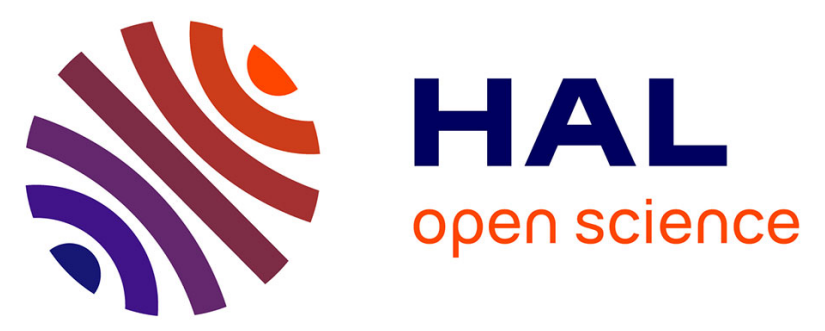

\title{
A high-throughput fluorescence polarization assay to discover inhibitors of arenavirus and coronavirus exoribonucleases
}

\author{
Sergio Hernández, Mikael Feracci, Carolina Trajano de Jesus, Priscila \\ El-Kazzi, Rafik Kaci, Laura Garlatti, Etienne Decroly, Bruno Canard, \\ Francois Ferron, Karine Alvarez
}

\section{To cite this version:}

Sergio Hernández, Mikael Feracci, Carolina Trajano de Jesus, Priscila El-Kazzi, Rafik Kaci, et al.. A high-throughput fluorescence polarization assay to discover inhibitors of arenavirus and coronavirus exoribonucleases. 2021. hal-03411674

\section{HAL Id: hal-03411674 \\ https://hal-amu.archives-ouvertes.fr/hal-03411674}

Preprint submitted on 2 Nov 2021

HAL is a multi-disciplinary open access archive for the deposit and dissemination of scientific research documents, whether they are published or not. The documents may come from teaching and research institutions in France or abroad, or from public or private research centers.
L'archive ouverte pluridisciplinaire HAL, est destinée au dépôt et à la diffusion de documents scientifiques de niveau recherche, publiés ou non, émanant des établissements d'enseignement et de recherche français ou étrangers, des laboratoires publics ou privés. 


\title{
1 A high-throughput fluorescence polarization assay to discover inhibitors of
}

2

3

4

6

7

\section{arenavirus and coronavirus exoribonucleases.}

Sergio Hernández, Mikael Feracci, Carolina Trajano De Jesus, Priscila El-Kazzi, Rafik Kaci, Laura Garlatti, Etienne Decroly, Bruno Canard, François Ferron* and Karine Alvarez*

Université Aix-Marseille, Architecture et Fonction des Macromolécules Biologiques (AFMB) - UMR7257

CNRS - Case 932, 163 avenue de Luminy, Marseille CEDEX 09, 13288, France.

\begin{abstract}
*Address correspondence to: Karine Alvarez and François Ferron, AFMB, Case 932, 163 avenue de Luminy, 13288 Marseille Cedex 9, France, Tel:+33-491-825570, Fax:+33-491-266720, Email: karine.alvarez@univamu.fr and francois.ferron@univ-amu.fr.
\end{abstract}

Abstract

Viral exoribonucleases are uncommon in the world of RNA viruses. To date, this activity has been identified only in the Arenaviridae and the Coronaviridae families. These exoribonucleases play important but different roles in both families: for mammarenaviruses the exoribonuclease is involved in the suppression of the host immune response whereas for coronaviruses, exoribonuclease is both involved in a proofreading mechanism ensuring the genetic stability of viral genomes and participating to evasion of the host innate immunity. Because of their key roles, they constitute attractive targets for drug development. Here we present a high-throughput assay using fluorescence polarization to assess the viral exoribonuclease activity and its inhibition. We validate the assay using three different viral enzymes from SARS-CoV-2, lymphocytic choriomeningitis and Machupo viruses. The method is sensitive, robust, amenable to miniaturization (384 well plates) and allowed us to validate the proof-of-concept of the assay by screening a small focused compounds library (23 metal chelators). We also determined the $\mathrm{IC}_{50}$ of one inhibitor common to the three viruses. 
Keywords

Phosphohydrolase activity, Arenaviridae, Coronaviridae, exoribonuclease activity, fluorescence polarization, screening, inhibitors, $\mathrm{IC}_{50}$.

\section{Highlights}

- Arenaviridae and Coronaviridae viral families share an exoribonuclease activity of common evolutionary origin

- Arenaviridae and Coronaviridae exoribonuclease is an attractive target for drug development

- We present a high-throughput assay in 384 well-plates for the screening of inhibitors using fluorescence polarization

- We validated the assay by screening of a focused library of 23 metal chelators against SARS-CoV-2, Lymphocytic Choriomeningitis virus and Machupo virus exoribonucleases

- We determined the $\mathrm{IC}_{50}$ by fluorescence polarization of one inhibitor common to the three viruses.

\section{Introduction}

RNA viruses code for a polyprotein, forming the replication/transcription complex (RTC) that orcherstrates viral replication. In this complex process, specific viral enzymatic activities are only found in some RNA viruses families. This is the case for the 3'-5'-exoribonuclease (ExoN) activity identified in Arenaviridae and Coronaviridae viral families, although these viruses display very different genome organization and replication/transcription strategies. Indeed, arenaviruses have an ambisense bi-segmented negative singlestranded RNA genome whereas the coronavirus genome is composed of a positive single-stranded RNA (Ferron et al., 2017; Knipe and Howley, 2013, Ogando et al., 2019). The ExoN activity identified in these two viral families are involved in different processes (Hastie et al., 2011; Snijder et al., 2003). Indeed, the ExoN carried by arenavirus nucleoprotein (NP) is likely involved in the suppression of the host innate immune response (Martínez-Sobrido et al., 2009, 2007, 2006) while the ExoN carried by the nsp14 protein of coronaviruses allows optimization of the replication fidelity of the viral genome (Bouvet et al., 2012; Ferron et al., 2018) as well as evasion of the host innate immunity (Becares et al., 2016; Lei et al., 2020). 
The arenavirus and coronavirus ExoN belong to the same DEDD superfamily (DED/EDh subfamily), are structurally similar (Zuo and Deutscher, 2001) and are characterized by the presence of four conserved acidic residues (Asp and Glu) (Bouvet et al., 2012; Yekwa et al., 2019). The catalytic residues are essential for the binding of two metal cations involved in the RNA hydrolysis mechanism (Steitz and Steitz, 1993), always proceeding from the 3 '- to the 5 '-direction.

Because of its biological significance to the viral life cycle and role in infectious processes, arenavirus and coronavirus ExoN is an attractive target for drug development (Papageorgiou et al., 2020; Subissi et al., 2014). Currently, there are almost no FDA-approved antivirals against these viruses, despite the loss of human lives during the short-lived SARS-CoV outbreak in 2002 and the continuing MERS epidemic or regular outbreaks of LASSA virus in West Africa causing several thousand case fatalities. Today, the situation is different, the world is paralyzed by a global SARS-CoV-2 pandemic and this event revealed the urgency to act to develop potent antivirals, in support of a vaccine approach.

While millions of molecules are available in countless compounds libaries, drug development efforts are generally restricted by the limitations of validated therapeutic targets or available potent high-throughput screening assays. For mammarenavirus and coronavirus ExoN assay making use of radiolabeled substrate are available but barely adapted to HT screening (Bouvet et al., 2012; Ferron et al., 2018; Yekwa et al., 2019, 2017; Baddock et al., 2020; Saramago et al., 2021)).

Here we present a method using fluorescence polarization (FP) to assess the ExoN activity and its inhibition. The method relies on the hydrolysis of a fluorescent RNA substrate into smaller fragments which translates in a modification of the FP signal which is measured and recorded. The FP signal is altered proportionally to the size of the fluorescent RNA probe. We validate the method on three different viral enzymes of interest from SARS-CoV-2, Lymphocytic Choriomeningitis and Machupo viruses. The method is sensitive, robust, amenable to miniaturization (384 well plates) and allowed us to screen a focused library of 23 metal chelators over the three targeted viral ExoN, validating the proof-of-concept of the assay. We also determined the $\mathrm{IC}_{50}$ of one inhibitor common to the three viruses.

\section{Materials and methods}

\subsection{Products and reagents.}


85

Raltegravir (1) and Baloxavir (5) were purchased from Carbosynth. Aurintricarboxyclic acid (11) was purchased from Acros Organics. Excepting for the compounds 8, 13, 14, 15 and 24, the other compounds have been described previously (Saez-Ayala et al., 2019, 2018). All compounds were resuspended in $100 \%$ DMSO at $20 \mathrm{mM}$ and stored at - $20{ }^{\circ} \mathrm{C}$. The 22-mer RNA 5'-UGACGGCCCGGAAAACCGGGCC-3' containing FAM dye at the 5'-end (5'-FAM-RNA) was purchased from Microsynth AG (Switzerland).

\subsection{Protein expression and purification.}

The LCMV, MACV, ExoN plasmids used for this study were described in (Yekwa et al., 2019). The protein production method is detailed in the supplementary data file (see also figure $\mathrm{S} 1$ for elution profiles). For the expression of the SARS-CoV-2 nsp10 and nsp14, the synthetic genes were purchased from Twist (USA) and were cloned with a hexahistidine tag in the N-terminus of the protein. E. coli DE3 cells were transformed with the corresponding expression vectors. Bacteria were grown in TB medium with the corresponding antibiotic and protein expression was induced by addition of IPTG to a final concentration of $500 \mu \mathrm{M}$ for nsp10 and $50 \mu \mathrm{M}$ for nsp14 when the $\mathrm{OD}_{600 \mathrm{~nm}}$ of the culture reached a value of 0.5 . The induction was performed during $16 \mathrm{~h}$ at $17^{\circ} \mathrm{C}$ and $200 \mathrm{rpm}$. Bacterial cell pellets were frozen and resuspended in lysis buffer (50 mM HEPES, pH 7.5 and $300 \mathrm{mM} \mathrm{NaCl}$ ) supplemented with $1 \mathrm{mM}$ PMSF, $10 \mathrm{mM}$ imidazole, 10 $\mu \mathrm{g} / \mathrm{ml}$ DNase I, $0.25 \mathrm{mg} / \mathrm{ml}$ of lysozyme and $0.5 \%$ Triton X-100. After sonication and clarification, proteins were purified by two steps of chromatography. The first step consisted of an IMAC (Ni Resin). The lysate was passed through the column and washed with lysis buffer supplemented with $20 \mathrm{mM}$ imidazole. The protein was eluted with lysis buffer supplemented with $250 \mathrm{mM}$ imidazole. Protein fractions were then loaded on a HiLoad 16/60 Superdex 200 gel filtration column (GE Healthcare), and eluted with $10 \mathrm{mM}$ HEPES, pH 7.5, $300 \mathrm{mM} \mathrm{NaCl}, 1 \mathrm{mM}$ DTT and 5\% glycerol. The fraction containing the pure protein, as examined by SDS-PAGE and coomasie staining, were pooled and concentrated in the gel filtration buffer, aliquoted in small volumes, flash frozen in liquid nitrogen and stored at $-80^{\circ} \mathrm{C}$.

\subsection{Set-up of exonuclease activity conditions based on fluorescent polarization assay}

\subsubsection{Optimisation of 5'-FAM-RNA concentration and SARS-CoV-2, LCMV or MACV ExoN ratio}

Reactions were performed in $20 \mu \mathrm{l}$ total volume in a buffer containing $40 \mathrm{mM}$ Tris (pH 8), $5 \mathrm{mM}$ DTT and 2 or $5 \mathrm{mM} \mathrm{MnCl}$. The concentration of 5'-FAM-RNA tested varied from 50 to $1000 \mathrm{nM}$. For each 5'-FAM- 
114

115

116

117

118

RNA concentration $(50,100,250,500$ and $1000 \mathrm{nM}$ ), a range of concentration of ExoN (SARS-CoV-2, LCMV or MACV) was tested from a ratio of 5-fold less enzyme up to 10-fold more enzyme (10 nM to 10 uM) than 5'-FAM-RNA. For SARS-CoV-2 ExoN, the molar ratio of nsp14:nsp10 complex in the reactions was always kept at 1:4, as optimized previously (Bouvet et al., 2012). The reaction started by the addition of 5'-FAM-RNA and the fluorescence polarization (FP) was read in the Pherastar FSX (BMG Labtech) using the $480 \mathrm{~nm}$ excitation and $520 \mathrm{~nm}$ emission filter, during 30 minutes at $25^{\circ} \mathrm{C}$, every 30 seconds. The gain was set up using the negative control which contained the fluorescent RNA in the reaction buffer with metal ion and in the presence of heat-denatured nuclease. Other negative controls tested used consisted in the replacement of $\mathrm{MnCl}_{2}$ by $\mathrm{CaCl}_{2}$ or, depletion of the metal ion in the reaction mix and depletion of the enzyme. After 30 minutes, the reactions were stopped by the addition of an equal volume of loading buffer (8M urea containing $10 \mathrm{mM}$ EDTA) and the digestion products were then loaded in $7 \mathrm{M}$ urea containing $20 \%$ (wt/vol) polyacrylamide gels (acrylamide/bisacrylamide ratio 19:1) buffered with TBE and visualized using a Fluorescent Image Analyzer Typhoon (GE Healthcare).

\subsubsection{Optimisation of temperature, metal ion nature and concentration requirement}

To find the optimal temperature, metal ion nature and reagent concentration, reactions were performed in the buffer mentioned above. The 5'-FAM-RNA concentration was kept at $100 \mathrm{nM}$ and ExoN concentration ranged from $100 \mathrm{nM}$ to $1600 \mathrm{nM}$. The activity was tested in the presence of $\mathrm{MnCl}_{2}$ or $\mathrm{MgCl}_{2}$ at three different concentrations 1,2 or $5 \mathrm{mM}$. The FP signal was recorded as mentioned previously either at $25^{\circ} \mathrm{C}$ or at $37^{\circ} \mathrm{C}$. After finishing the recording of the FP signal, an aliquot of the sample was examined in urea PAGE as mentioned above.

\subsubsection{Time course of ExoN assay}

Reactions of $20 \mu \mathrm{l}$ total volume were performed in the buffer mentioned above, with $2 \mathrm{mM} \mathrm{MnCl}_{2}$ for SARS-CoV-2 ExoN and $5 \mathrm{mM}$ for LCMV or MACV ExoN. The 5'-FAM-RNA concentration was fixed at $100 \mathrm{nM}$. The SARS-CoV-2 nsp14/nsp10 ExoN complex concentration was ranged from $200 \mathrm{nM}$ to $1 \mu \mathrm{M}$ and pre-incubation at RT during 5 minutes was performed to allow the complex formation. The LCMV and MACV ExoN concentration was ranged from $100 \mathrm{nM}$ to $1600 \mathrm{nM}$. The reaction started by the addition of 5'FAM-RNA and The FP signal was recorded as mentioned previously. After finishing the recording of the FP 
143

144

145

146

147

148

149

150

151

152

153

154

155

156

157

158

160

161

162

163

164

165

166

167

signal, an aliquot of the sample was examined in urea PAGE as mentioned above. The assay was done in triplicate for each ExoN.

\subsection{High throughput screening and $I C_{50}$ determination.}

\subsubsection{HTS assay based on fluorescent polarization assay}

The screening at $5 \mu \mathrm{M}$ and $20 \mu \mathrm{M}$ inhibitor concentration was performed in 384-wells with flat bottom Nunc plates, in $20 \mu \mathrm{L}$ total volume reaction. Reactions were performed in a buffer containing $40 \mathrm{mM}$ Tris (pH 8), $5 \mathrm{mM}$ DTT, with $2 \mathrm{mM} \mathrm{MnCl}{ }_{2}$ for SARS-CoV-2 and $5 \mathrm{mM} \mathrm{MnCl}_{2}$ for LCMV or MACV ExoN. The 5'FAM-RNA concentration was fixed at $100 \mathrm{nM}$. The ExoN concentration was fixed at $400 \mathrm{nM}$. Compounds (1-23) were added to the reaction with final concentration of $5 \mu \mathrm{M}$ and $20 \mu \mathrm{M}$ in 5\% DMSO. Reactions were initiated by addition of the 5'-FAM-RNA using a multichannel pipette. 48 positive controls (the reaction mix with 5\% DMSO, with ExoN and without compound) have been deposited randomly in the 384-well plate. 48 negative controls (the reaction mixture with 5\% DMSO, without or with ExoN that has been heat denatured, and without compound), have been deposited randomly in the 384-well plate. The reaction started by the addition of 5'-FAM-RNA and the FP signal was recorded as mentioned previously. To calculate the percentage of inhibition, a time correction was applied for the delayed initiation of the reaction due to the use of a multichannel pipette. The percentage of inhibition at a given time was calculated as follows :

$$
\text { Inhibition } \%=\frac{100 \times(F P-\text { average of positive controls })}{(\text { average negative controls-average positive controls })}
$$

where FP correspond to the fluorescent polarization signal of a compound.

The time selected for doing this calculation was the time when the signal of the positive control reached the plateau (30 minutes). The Z' factor for the assay was calculated using the following equation:

$$
Z^{\prime}=1-\frac{3 \times(S D \text { of negative controls }+S D \text { of positive controls })}{(\text { mean of negative controls }- \text { mean of positive controls })}
$$

where SD is the standard deviation. 48 positive controls and 48 negative controls were considered to calculate the Z' factor.

2.4.2 IC So determination of compound 11 based on fluorescent polarization assay 
168

169

170

171

172

173

174

175

176

177

178

179

180

181

182

183

184

185

186

187

188

189

190

191

192

193

Reactions were performed in a buffer containing $40 \mathrm{mM}$ Tris ( $\mathrm{pH} 8$ ), $5 \mathrm{mM} \mathrm{DTT}$, with $2 \mathrm{mM} \mathrm{MnCl}_{2}$ for SARS-CoV-2 ExoN and $5 \mathrm{mM}$ for LCMV or MACV ExoN. The 5'-FAM-RNA concentration was fixed at $100 \mathrm{nM}$. The ExoN concentration was fixed at $400 \mathrm{nM}$. The compound 11 concentration varied from 0.2 to $12.5 \mu \mathrm{M}$ for LCMV ExoN, from 0.4 to $25 \mu \mathrm{M}$ for MACV ExoN and from 0.5 to $16 \mu \mathrm{M}$ for SARS-CoV-2 ExoN nsp14/nsp10 complex. The reaction started by the addition of 5'-FAM-RNA and the FP signal was recorded as mentioned previously. The percentage of inhibition was calculated as indicated in the previous section. The curves of percentage of inhibition respect to the inhibitor concentration in a logarithmic scale were fitted in Graphpad Prism software using a four parameters equation. The assays were done in triplicate.

3. Results and discussion

Fluorescence polarization (FP) is a reliable and sensitive tool for monitoring enzymatic reaction progress, by determining the difference of polarization signals during reaction (Zhang et al., 2012). FP based assays in HTS studies have been used in drug discovery (Lea and Simeonov, 2011; Uri and Nonga, 2020, Baughman et al., 2012; Liu et al., 2014)). The FP signal recorded is proportional to the molecular weight (MW) of a fluorescent molecule (Kwok, 2002; Latif et al., 2001). We decided to apply this method to viral ExoN activity, by monitoring the size of a fluorescent labeled RNA probe which is altered in the course of the nuclease activity, reflecting the enzymatic activity (Liu et al., 2014; Zhang et al., 2012). Because several factors can change the FP- monitoring success, the assay was first optimized.

3.1 Determination of optimized experimental conditions of the SARS-CoV-2 nsp14/nsp10 complex, LCMV and MACV ExoN activity based on FP assay

To set-up a HTS assay for the SARS-CoV-2, LCMV and MACV ExoN activity, we explored 5'-FAM-RNA substrate(s) and enzyme(s) concentration, metal ion co-factors, temperature and reaction duration. RNA substrate and optimal conditions for arenavirus and coronavirus ExoN activity are already described (Bouvet et al., 2012; Saramago et al., 2021; Yekwa et al., 2019, 2017). A 22mer RNA that forms stable hairpin in its 3' end has been reported to be a valuable substrate for both arenavirus and coronavirus ExoN. Moreover, for SARS-CoV-2 nsp14 ExoN, nsp10 was added in the reaction (ratio 1:4 of nsp14:nsp10) as nsp10 was 
197

198

199

200

201

202

203

204

205

206

207

208

209

210

211

212

213

214

215

216

217

218

219

220

221

222

223

224

225

previously demonstrated to stimulate > 35-fold the nsp14 ExoN activity (Bouvet et al., 2012; Saramago et al., 2021).

We first determined the smallest 5'-FAM-RNA concentration that provides sufficient FP signal, concomitantly with the set-up of the ratio of ExoN and 5'-FAM-RNA to obtain a reproducible and stable FP signal. For each 5'-FAM-RNA concentration tested (50 to $1000 \mathrm{nM}$ ), single turn over (STO) conditions (excess of enzyme respect to substrate) and also multiple turn over (MTO) conditions (excess of substrate respect to enzyme) were tested. Because the RNA substrate is degraded during the ExoN activity, FP value is altered proportionally. A significant change in the FP signal due to the hydrolysis of the 5'-FAM-RNA was observed only under STO conditions. $100 \mathrm{nM}$ concentration of 5'-FAM-RNA was selected because it was the smallest concentration of substrate providing a reproducible and stable FP signal.

We optimized the positive and negative controls of ExoN activity. Several combinations were tested (Supplementary figure S2): 5'-FAM-RNA in reaction buffer with metal ions, 5'-FAM-RNA in reaction buffer with ExoN and without metal ions, 5'-FAM-RNA in reaction buffer with ions and denaturated ExoN and 5'FAM-RNA in reaction buffer with $\mathrm{CaCl}_{2}$ instead of $\mathrm{MnCl}_{2}$. For all the negative controls tested, there was no variation between the initial and final FP values after $30 \mathrm{~min}$ incubation, indicating the absence of degradation of the fluorescent probe. However, we observe that the initial FP values are lower without metal ions in the reaction buffer (Supplementary figure S2), or in the presence of EDTA $10 \mathrm{mM}$ (data not shown). This results is in agreement with the study of Liu et al (Liu et al., 2014), who carried out the experiments to investigate the influence of metal ions in FP assays, and reported that cations concentration can affect the FP signal by altering the mobility of the fluorophore through stabilizing the RNA secondary structure. Thus, for the rest of the study, the negative controls were prepared by mixing 5'-FAM-RNA in reaction buffer with ions and without ExoN.

Regarding the nature of the metal ion, $\mathrm{MnCl}_{2}$ and $\mathrm{MgCl}_{2}$ were tested. An increased activity is observed in the presence of $\mathrm{MnCl}_{2}$ for both arenaviruses and SARS-CoV-2 ExoN (data not shown). The concentration of $\mathrm{MnCl}_{2}$ that shows the highest reduction in FP signal is $5 \mathrm{mM}$ for arenaviruses as previously reported (Yekwa et al., 2019, 2017) and $2 \mathrm{mM}$ for SARS-CoV-2 as recently reported (Baddock et al., 2020; Saramago et al., 2021). Finally the temperature selected to perform the assay is $25^{\circ} \mathrm{C}$ since the incubation at $37^{\circ} \mathrm{C}$ leads to a significative evaporation of the sample that reduces the stability and reproducibility of the FP signal. 
While the 5'-FAM-RNA substrate was fixed at $100 \mathrm{nM}$, which was the lowest concentration fairly detected by the sensitivity of the method, different concentrations of ExoN were tested (100 nM to $1600 \mathrm{nM})$. The FP signal change was measured during $30 \mathrm{~min}$. The FP curves and digestion products examined in urea PAGE after FP reading, are gathered in figure 1.

The negative controls (figure 1, brown curves, in panels A, B and C) present flattened curves, as expected. Remarkably, early in the reaction a small increase in the initial FP value is observed, which could correspond to the time required for the formation of the catalytic complex between the ExoN, the catalytic cations and the 5'-FAM-RNA substrate. This is more visible for the SARS-CoV-2 ExoN, which requires the interaction of nsp14 and nsp10 forming the active complex. This increase of fluorescence occurs for all FP curves but is visible mainly on the FP curves corresponding to the lowest ExoN concentrations when the formation of the pre-hydrolytic complex presumably takes the longest time.

For all tested ExoN, excepting for the lowest used concentration, we observe a reduction of the FP signal with time. The decrease of the FP value is correlated with the hydrolysis of the 5'-FAM-RNA substrate by initial and final FP value after $30 \mathrm{~min}$ is proportional to the number of nucleotides removed from the 5'-

\section{FAM-RNA.}

By increasing the ExoN concentration, we observe an increase in the FP curves slope but the FP signals reach a plateau which might be related to the inability to remove any extra nucleotide after a certain point.

The method efficiency was validated by the difference of FP values between the negative control (figure 1,

This difference was selected as significant enough, with $\Delta \mathrm{FP}+/-30$ units of $\mathrm{mP}$.

To validate this method and use it as screening assay, we decided to use a molar ratio 1:4 between the 5'-

FAM-RNA substrate $(100 \mathrm{nM})$ and ExoN (400 nM). With the optimized duration, temperature and experimental conditions, this ratio gives the more stable and reproducible FP signals, correlated with specific 5'-FAM-RNA fragments. 
Because ExoN activity is metal dependent, we tested a focused library of 23 metal chelators that we have developed previously (Saez-Ayala et al., 2019, 2018), in order to demonstrate the robustness of our FP method. Two screenings were performed using $5 \mu \mathrm{M}$ and $20 \mu \mathrm{M}$ of compounds in 5\% DMSO in a single assay. The robustness of the assay for HTS was calculated using 48 negative and 48 positive controls. The lowest $\mathrm{Z}^{\prime}$ value is 0.68 indicating that the assay is reliable (see supplementary data figure S3). The percentages of inhibition at $5 \mu \mathrm{M}$ and $20 \mu \mathrm{M}$ for each ExoN, extracted from FP curves (see supplementary data figure S4), are gathered in supplementary figure S5 and figure 2 (panels A, B and C), respectively. The degree of digestion of the RNA substrate was also controlled by fragments separation on urea-PAGE at the end of the reaction for compounds $4, \mathbf{1 1}, \mathbf{1 3}, \mathbf{1 8}$ and $\mathbf{2 3}$ (figure 2, panel D).

We identified compound $\mathbf{1 1}$ which inhibits $100 \%$ of the different ExoN activity at $20 \mu \mathrm{M}$ and $78 \%, 76 \%$ and $100 \%$ at $5 \mu \mathrm{M}$, respectively against LCMV, MACV and SARS-CoV-2 ExoN. Compound 11 which is Aurintricarboxyclic Acid (ATA) was included as positive control as it has been previously described as nuclease inhibitor (Huang et al., 2016), acting as non-specific metal chelator (Sharma et al., 2000). We also identified inhibitors showing more specific inhibition profile. Compound $\mathbf{4}$ is active against SARS-CoV-2 with $61 \%$ inhibition at $20 \mu \mathrm{M}$ (less than $10 \%$ inhibition of LCMV ExoN) while compound 23 is specific to LCMV ExoN with 71\% inhibition (less than 10\% inhibition of MACV ExoN). Compounds $\mathbf{1 3}$ and $\mathbf{1 8}$ are potent inhibitors of SARS-CoV-2 ExoN with more $90 \%$ and weak inhibitors of LCMV and MACV ExoN (less than $20 \%$ inhibition). The FP method allowed the identification of potent ExoN inhibitors as compounds $4, \mathbf{1 1}, \mathbf{1 3}, \mathbf{1 8}$ and $\mathbf{2 3}$, and the absence of RNA degradation was confirmed by urea PAGE analysis (figure 2 - panel D) used as an orthogonal validation assay.

\subsection{Assessing $I C_{50}$ measurement of compound 11 by FP}

277 Compound 11 displaying the highest inhibition, at both 5 and $20 \mu \mathrm{M}$, was used as model for $\mathrm{IC}_{50}$ 278 determination. The FP curves, the digestion products examined in urea PAGE after FP reading and dose279 response curves obtained by extraction of FP data are gathered in figure 3 . The $\mathrm{IC}_{50}$ values were determined by hill plot curve fitting (see materials and methods section). The $\mathrm{IC}_{50}$ values for LCMV, MACV and SARS- 
282

283

284

285

286

287

288

289

290

291

292

293

294

295

296

297

298

299

300

301

302

303

304

305

306

307

correlated perfectly with the $80 \%$ inhibition obtained by screening at $5 \mu \mathrm{M}$, confirming the robustness and reproducibility of the assay. The FP signal correlates also with the degree of digestion observed by gel.

4. Conclusion

The use of fluorescence polarization assay for inhibitors identification was investigated and we prove that this technique is reliable and sensitive to monitor nuclease activity.

Our work presents the development of a viral ExoN HTS assay in 384-well plates. Its most valuable feature is that allows a reliable and rapid identification of ExoN inhibitors limiting the ExoN activity of viral enzymes belonging to arenavirus (LCMV and MACV) and coronavirus (SARS-CoV-2).

These results make fluorescence polarization assay an important tool in the screening of compounds libraries to discover antivirals.

Funding and Acknowledgments

This work was supported by grants from the Ministry of the Armed Forces (DGA) - Defense Innovation Agency (AID) and the French National Research Agency (ANR-18-ASTR-0010-01, PaNuVi), Fondation pour la Recherche Medicale (Chemistry for Medecine, DCM20181039531), SCORE project H2020 SC1PHE Coronavirus-2020 (grant\#101003627). Priscila El-Kazzi and Rafik Kaci were funded by Fondation Mediterranée Infection (Infectiopole Sud), Laura Garlatti was funded by DGA and Aix-Marseille University (fellowship N DGA01D19024292 AID). The Carolina Trajano De Jesus master's internship was supported by the Coordenação de Aperfeiçoamento de Pessoal de Nível Superior - Brasil (CAPES) - Finance Code 001. We thank Thi Hong Van Nguyen and Adrien Delpal for technical assistance.

Supplementary data associated with this article can be found, in the online version, at

\section{References}

Baddock, H.T., Brolih, S., Yosaatmadja, Y., Ratnaweera, M., Bielinski, M., Swift, L.P., Cruz-Migoni, A., Morris, G.M., Schofield, C.J., Gileadi, O., McHugh, P.J., 2020. Characterisation of the SARS-CoV2 ExoN (nsp14ExoN-nsp10) complex: implications for its role in viral genome stability and inhibitor identification. bioRxiv 2020.08.13.248211. https://doi.org/10.1101/2020.08.13.248211 
Baughman, B.M., Jake Slavish, P., DuBois, R.M., Boyd, V.A., White, S.W., Webb, T.R., 2012. Identification of influenza endonuclease inhibitors using a novel fluorescence polarization assay. ACS Chem. Biol. 7, 526-534. https://doi.org/10.1021/cb200439z

Becares, M., Pascual-Iglesias, A., Nogales, A., Sola, I., Enjuanes, L., Zuñiga, S., 2016. Mutagenesis of Coronavirus nsp14 Reveals Its Potential Role in Modulation of the Innate Immune Response. J. Virol. 90, 5399-5414. https://doi.org/10.1128/JVI.03259-15

Bouvet, M., Imbert, I., Subissi, L., Gluais, L., Canard, B., Decroly, E., 2012. RNA 3'-end mismatch excision by the severe acute respiratory syndrome coronavirus nonstructural protein nsp10/nsp14 exoribonuclease complex. Proc. Natl. Acad. Sci. 109, 9372-9377. https://doi.org/10.1073/pnas.1201130109

Ferron, F., Subissi, L., Silveira De Morais, A.T., Le, N.T.T., Sevajol, M., Gluais, L., Decroly, E., Vonrhein, C., Bricogne, G., Canard, B., Imbert, I., 2018. Structural and molecular basis of mismatch correction and ribavirin excision from coronavirus RNA. Proc. Natl. Acad. Sci. U. S. A. 115, E162-E171. https://doi.org/10.1073/pnas.1718806115

Ferron, F., Weber, F., de la Torre, J.C., Reguera, J., 2017. Transcription and replication mechanisms of Bunyaviridae and Arenaviridae L proteins. Virus Res. 234, 118-134. https://doi.org/10.1016/j.virusres.2017.01.018

Hastie, K.M., Kimberlin, C.R., Zandonatti, M.A., MacRae, I.J., Saphire, E.O., 2011. Structure of the Lassa virus nucleoprotein reveals a dsRNA-specific $3^{\prime}$ to $5^{\prime}$ exonuclease activity essential for immune suppression. Proc. Natl. Acad. Sci. U. S. A. 108, $2396-2401$. https://doi.org/10.1073/pnas.1016404108

Knipe, D.M., Howley, P.M. (Eds.), 2013. Fields virology, 6th ed. ed. Wolters Kluwer/Lippincott Williams \& Wilkins Health, Philadelphia, PA.

Huang, K.-W., Hsu K.-C., Chu, L.-Y., Yang J.-M., Yuan H. S., Hsiao Y.-Y. 2016. Identification of Inhibitors for the DEDDh Family of Exonucleasesand a Unique Inhibition Mechanism by Crystal Structure Analysisof CRN-4 Bound with 2-Morpholin-4-ylethanesulfonate (MES). J. Med. Chem. 59, 80198029. https://doi.org/10.1021/acs.jmedchem.6b00794

Kwok, P.-Y., 2002. SNP genotyping with fluorescence polarization detection. Hum. Mutat. 19, $315-323$. https://doi.org/10.1002/humu.10058

Latif, S., Bauer-Sardina, I., Ranade, K., Livak, K.J., Kwok, P.Y., 2001. Fluorescence polarization in homogeneous nucleic acid analysis II: 5'-nuclease assay. Genome Res. 11, 436-440. https://doi.org/10.1101/gr.156601

Lea, W.A., Simeonov, A., 2011. Fluorescence polarization assays in small molecule screening. Expert Opin. Drug Discov. 6, 17-32. https://doi.org/10.1517/17460441.2011.537322

Lei, X., Dong, X., Ma, R., Wang, W., Xiao, X., Tian, Z., Wang, C., Wang, Y., Li, L., Ren, L., Guo, F., Zhao, Z., Zhou, Z., Xiang, Z., Wang, J., 2020. Activation and evasion of type I interferon responses by SARS-CoV-2. Nat. Commun. 11, 3810. https://doi.org/10.1038/s41467-020-17665-9

Liu, X., Chen, Y., Fierke, C.A., 2014. A real-time fluorescence polarization activity assay to screen for inhibitors of bacterial ribonuclease P. Nucleic Acids Res. 42, e159. https://doi.org/10.1093/nar/gku850

Martínez-Sobrido, L., Emonet, S., Giannakas, P., Cubitt, B., García-Sastre, A., de la Torre, J.C., 2009. Identification of Amino Acid Residues Critical for the Anti-Interferon Activity of the Nucleoprotein of the Prototypic Arenavirus Lymphocytic Choriomeningitis Virus. J. Virol. 83, 11330-11340. https://doi.org/10.1128/JVI.00763-09

Martínez-Sobrido, L., Giannakas, P., Cubitt, B., García-Sastre, A., Torre, J.C. de la, 2007. Differential Inhibition of Type I Interferon Induction by Arenavirus Nucleoproteins. J. Virol. 81, 12696-12703. https://doi.org/10.1128/JVI.00882-07

Martínez-Sobrido, L., Zúñiga, E.I., Rosario, D., García-Sastre, A., de la Torre, J.C., 2006. Inhibition of the Type I Interferon Response by the Nucleoprotein of the Prototypic Arenavirus Lymphocytic Choriomeningitis Virus. J. Virol. 80, 9192-9199. https://doi.org/10.1128/JVI.00555-06

Ogando, N.S., Ferron, F., Decroly, E., Canard, B., Posthuma, C.C., Snijder, E.J., 2019. The Curious Case of the Nidovirus Exoribonuclease: Its Role in RNA Synthesis and Replication Fidelity. Front. Microbiol. 10, 1813. https://doi.org/10.3389/fmicb.2019.01813

Papageorgiou, N., Spiliopoulou, M., Nguyen, T.-H.V., Vaitsopoulou, A., Laban, E.Y., Alvarez, K., Margiolaki, I., Canard, B., Ferron, F., 2020. Brothers in Arms: Structure, Assembly and Function of Arenaviridae Nucleoprotein. Viruses 12. https://doi.org/10.3390/v12070772 
Saez-Ayala, M., Laban Yekwa, E., Mondielli, C., Roux, L., Hernández, S., Bailly, F., Cotelle, P., Rogolino, D., Canard, B., Ferron, F., Alvarez, K., 2019. Metal chelators for the inhibition of the lymphocytic choriomeningitis virus endonuclease domain. Antiviral Res. 162, 79-89. https://doi.org/10.1016/j.antiviral.2018.12.008

Saez-Ayala, M., Yekwa, E.L., Carcelli, M., Canard, B., Alvarez, K., Ferron, F., 2018. Crystal structures of Lymphocytic choriomeningitis virus endonuclease domain complexed with diketo-acid ligands. IUCrJ 5, 223-235. https://doi.org/10.1107/S2052252518001021

Saramago, M., Bárria, C., Costa, V., Souza, C.S., Viegas, S.C., Domingues, S., Lousa, D., Soares, C.M., Arraiano, C.M., Matos, R.G., 2021. New targets for drug design: Importance of nsp14/nsp10 complex formation for the 3'-5' exoribonucleolytic activity on SARS-CoV-2. bioRxiv 2021.01.07.425745. https://doi.org/10.1101/2021.01.07.425745

Sharma, R.K., Garg, B.S., Kurosaki, H., Goto, M., Otsuka, M., Yamamoto, T., Inoue, J., 2000. Aurine tricarboxylic acid, a potent metal-chelating inhibitor of NFkappaB-DNA binding. Bioorg. Med. Chem. 8, 1819-1823. https://doi.org/10.1016/s0968-0896(00)00109-7

Snijder, E.J., Bredenbeek, P.J., Dobbe, J.C., Thiel, V., Ziebuhr, J., Poon, L.L.M., Guan, Y., Rozanov, M., Spaan, W.J.M., Gorbalenya, A.E., 2003. Unique and Conserved Features of Genome and Proteome of SARS-coronavirus, an Early Split-off From the Coronavirus Group 2 Lineage. J. Mol. Biol. 331, 991-1004. https://doi.org/10.1016/S0022-2836(03)00865-9

Steitz, T.A., Steitz, J.A., 1993. A general two-metal-ion mechanism for catalytic RNA. Proc. Natl. Acad. Sci. U. S. A. 90, 6498-6502. https://doi.org/10.1073/pnas.90.14.6498

Subissi, L., Imbert, I., Ferron, F., Collet, A., Coutard, B., Decroly, E., Canard, B., 2014. SARS-CoV ORF1bencoded nonstructural proteins 12-16: replicative enzymes as antiviral targets. Antiviral Res. 101, 122-130. https://doi.org/10.1016/j.antiviral.2013.11.006

Uri, A., Nonga, O.E., 2020. What is the current value of fluorescence polarization assays in small molecule screening? Expert Opin. Drug Discov. 15, 131-133. https://doi.org/10.1080/17460441.2020.1702966

Yekwa, E., Aphibanthammakit, C., Carnec, X., Picard, C., Canard, B., Baize, S., Ferron, F., 2019. Arenaviridae exoribonuclease presents genomic RNA edition capacity. bioRxiv 541698. https://doi.org/10.1101/541698

Yekwa, E., Khourieh, J., Canard, B., Papageorgiou, N., Ferron, F., 2017. Activity inhibition and crystal polymorphism induced by active-site metal swapping. Acta Crystallogr. Sect. Struct. Biol. 73, 641649. https://doi.org/10.1107/S205979831700866X

Zhang, M., Le, H.-N., Wang, P., Ye, B.-C., 2012. A versatile molecular beacon-like probe for multiplexed detection based on fluorescence polarization and its application for a resettable logic gate. Chem. Commun. Camb. Engl. 48, 10004-10006. https://doi.org/10.1039/c2cc35185d

Zuo, Y., Deutscher, M.P., 2001. Exoribonuclease superfamilies: structural analysis and phylogenetic distribution. Nucleic Acids Res. 29, 1017-1026. 
411

412

413

414

415

416

417

418

419

420

421

422

423

424

425

426

427

428

429

430

431

432

433

434

435

436

Legend to figures

Figure 1. ExoN activity measured by FP for LCMV (panel A), MACV (panel B) and SARS-CoV-2 (panel C). The FP signal variation is recorded with time during 30 min, each 30 secondes, at $25^{\circ} \mathrm{C}$. The $5^{\prime}-\mathrm{FAM}-$ RNA substrate concentration used is $100 \mathrm{nM}$ and the ExoN concentration tested ranges $100 \mathrm{nM}$ to $1600 \mathrm{nM}$. The data represents the average and SEM of three independent experiments. The bottom panels illustrate a representative image of the digestion products analyzed in urea PAGE, of the ExoN activity for LCMV (panel D), MACV (panel E) and SARS-CoV-2 (panel F), after recording the FP signal. An aliquot of the sample was loaded into a urea-PAGE $20 \%$ and scanned in a fluorescence imager.

Figure 2. Screening of focused library of metal chelators (23) against LCMV (panel A), MACV (panel B) and SARS-CoV-2 (panel C) ExoN followed by FP. Orthogonal validation assay by analysis of the fluorescent RNA substrate by urea PAGE (panel D) The bars show the \% of inhibition of the ExoN activity as described in materials and methods. For the screening conditions $100 \mathrm{nM}$ 5'-FAM-RNA, $400 \mathrm{nM}$ ExoN and $20 \mu \mathrm{M}$ of inhibitor were used.

Figure 3. IC $_{50}$ measurement of compound 11 by FP on LCMV, MACV and SARS-CoV-2 ExoN. In A, B and $\mathrm{C}$ the FP signal variation is recorded with time during $30 \mathrm{~min}$, each 30 seconds, at $25^{\circ} \mathrm{C}$. The $5^{\prime}$-FAM-RNA substrate and LCMV (panel A), MACV (panel B) and SARS-CoV-2 (panel C) ExoN concentration were respectively $100 \mathrm{nM}$ and $400 \mathrm{nM}$. The data represents the average and SEM of three independent experiments. In the middle panels it is shown a representative image of the digestion products of the LCMV (panel D), MACV (panel E) and SARS-CoV-2 (panel F) ExoN in presence of the different concentrations of compound 11, visualized in urea AGE after recording the FP signal. In the bottom panels it is shown the dose-response curves obtained by extraction of FP data, the $\mathrm{IC}_{50}$ values for compound $\mathbf{1 1}$ with LCMV (panel G), MACV (panel H) and SARS-CoV-2 (panel I). The data represents the average and SEM of three independent experiments. 


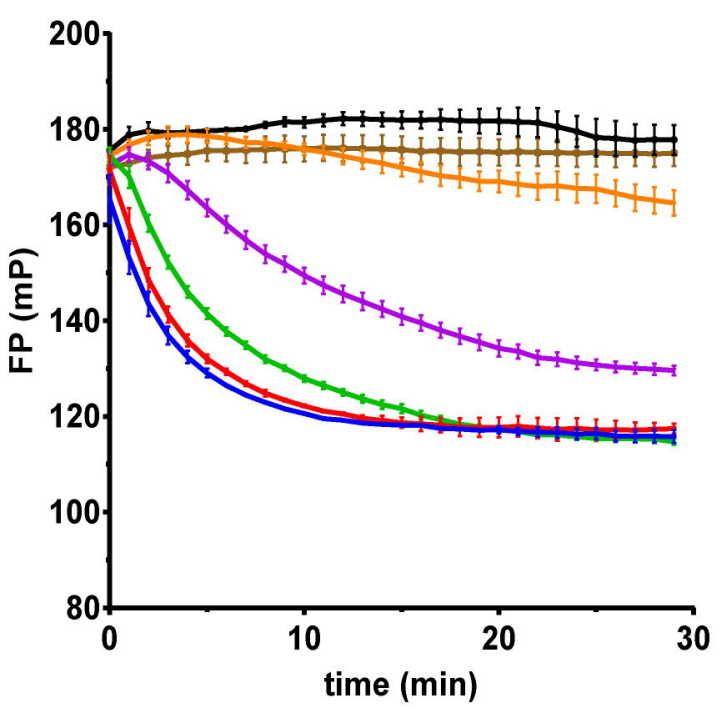

D)

LCMV ExoN ( $\mu \mathrm{M})$

$\begin{array}{lllllll}1.6 & 1.2 & 0.8 & 0.4 & 0.2 & 0.1 & 0\end{array}$

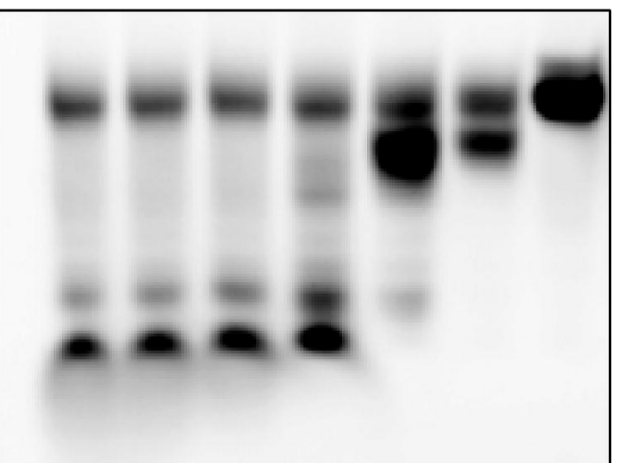

$-1.6 \mu \mathrm{M}$

$-1.2 \mu \mathrm{M}$

$-0.8 \mu \mathrm{M}$

$-0.2 \mu \mathrm{M}$

$-0.1 \mu \mathrm{M}$

- no enzyme

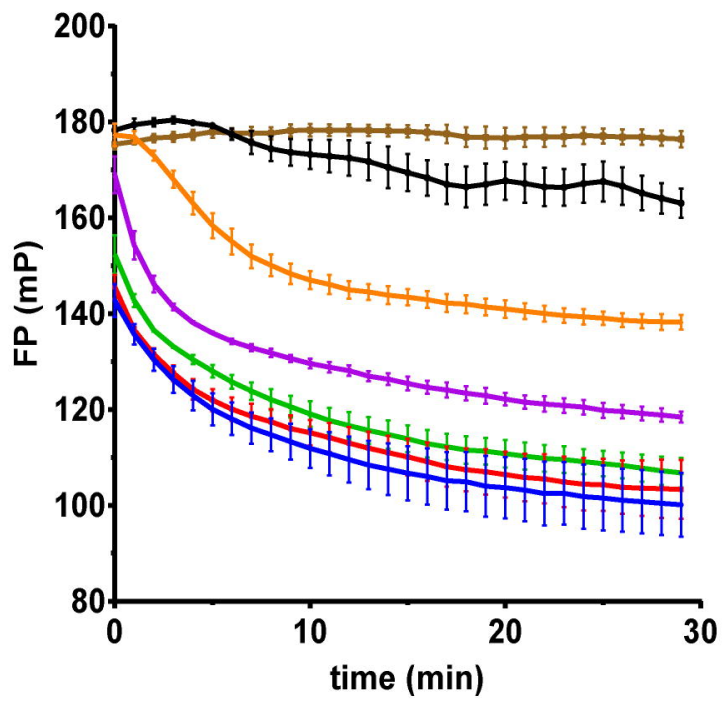

$-1.6 \mu \mathrm{M}$

$-1.2 \mu \mathrm{M}$

$-0.8 \mu \mathrm{M}$

$-0.4 \mu \mathrm{M}$

$-0.2 \mu \mathrm{M}$
$-0.1 \mu \mathrm{M}$

- no enzyme

C)

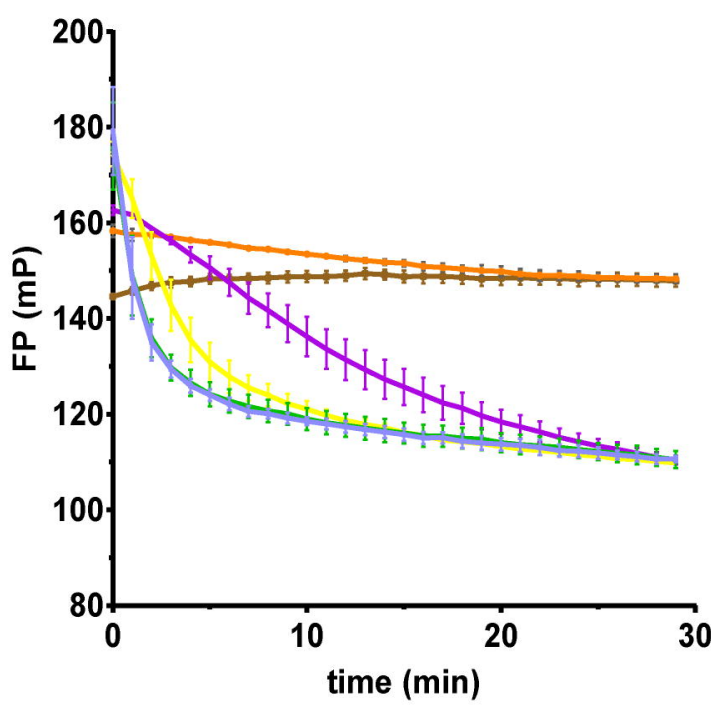

$-1.0 \mu \mathrm{M}$

$-0.8 \mu \mathrm{M}$

$-0.6 \mu \mathrm{M}$

$-0.4 \mu \mathrm{M}$

$-0.2 \mu \mathrm{M}$

- no enzyme

E)

MACV ExoN $(\mu \mathrm{M})$

$\begin{array}{lllllll}1.6 & 1.2 & 0.8 & 0.4 & 0.2 & 0.1 & 0\end{array}$

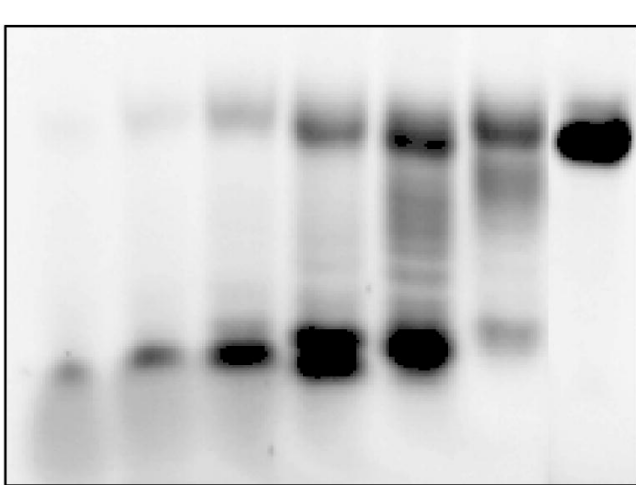

F)

SARS-CoV-2nsp14 ( $\mu \mathrm{M})$

$\begin{array}{llllll}1.0 & 0.8 & 0.6 & 0.4 & 0.2 & 0\end{array}$

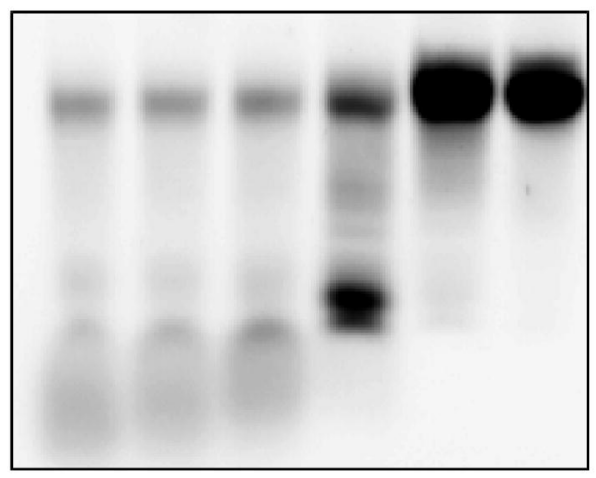




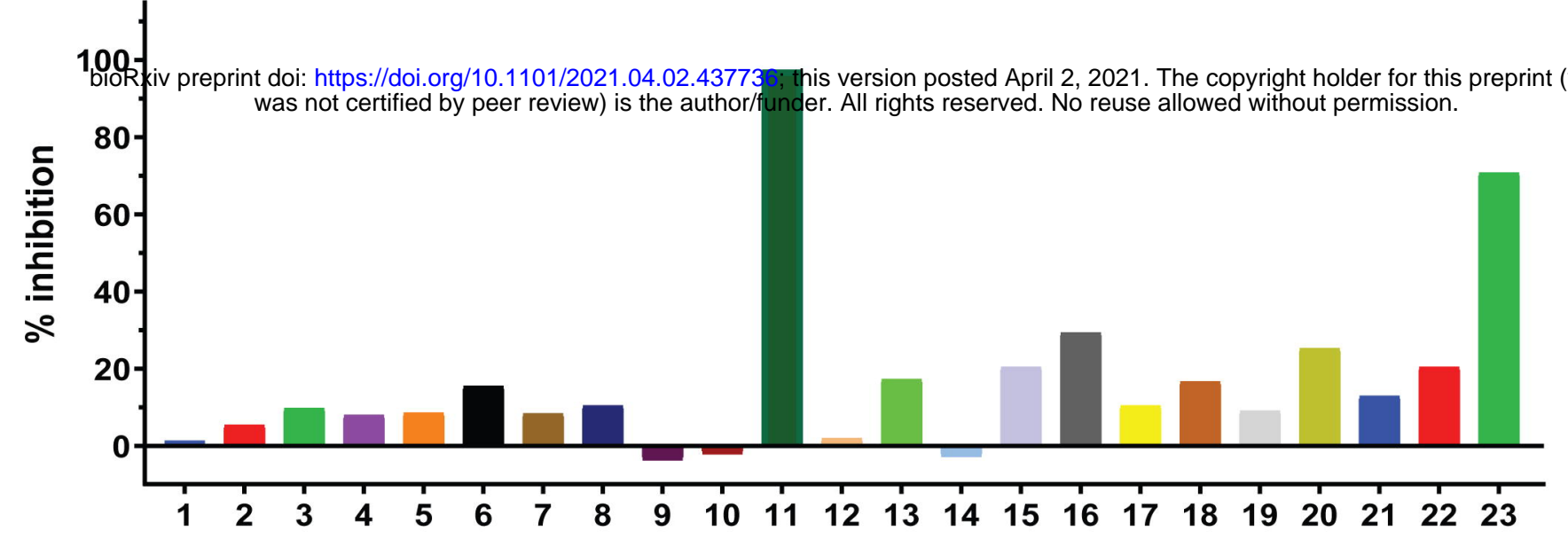

B)

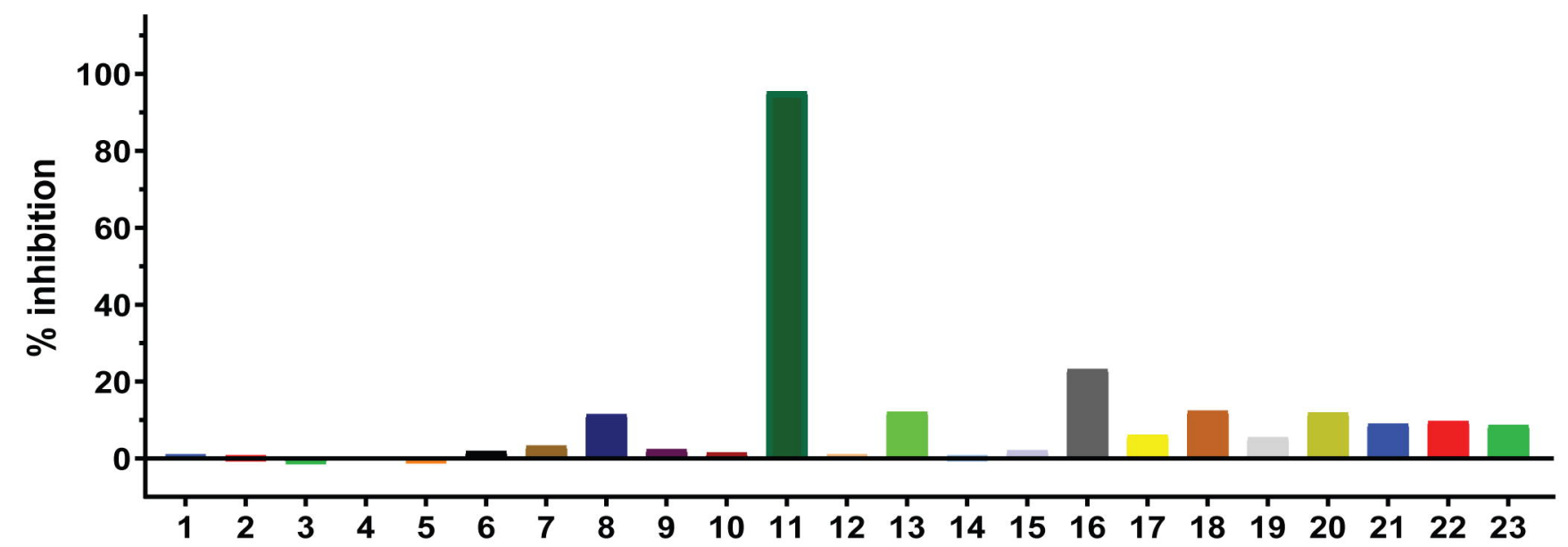

C)

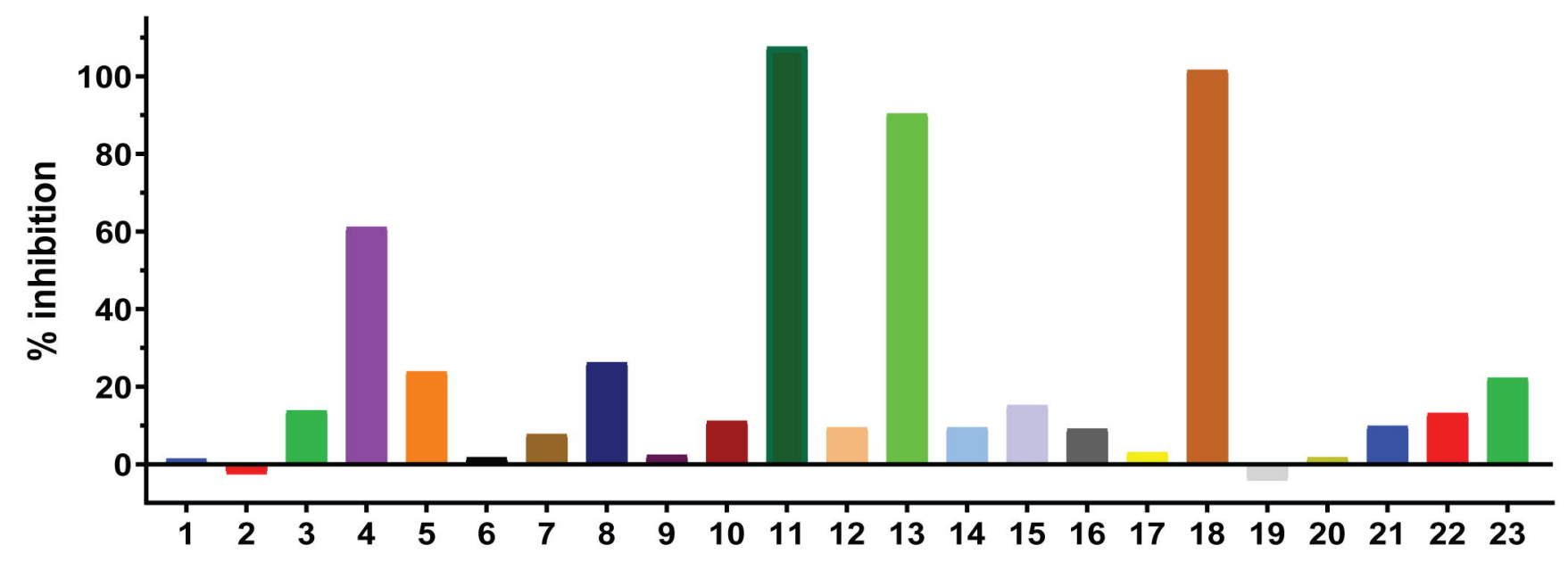

D)
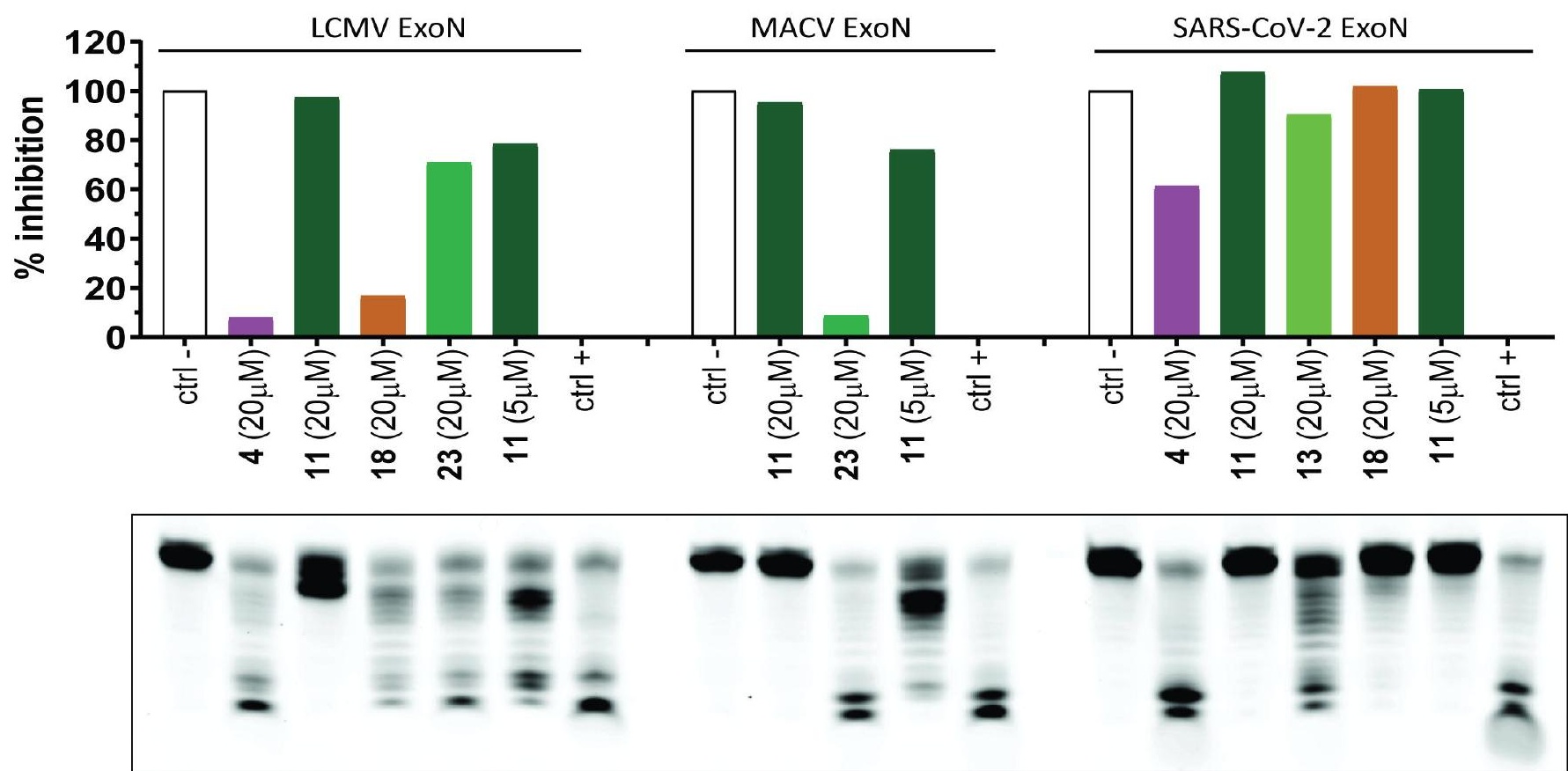


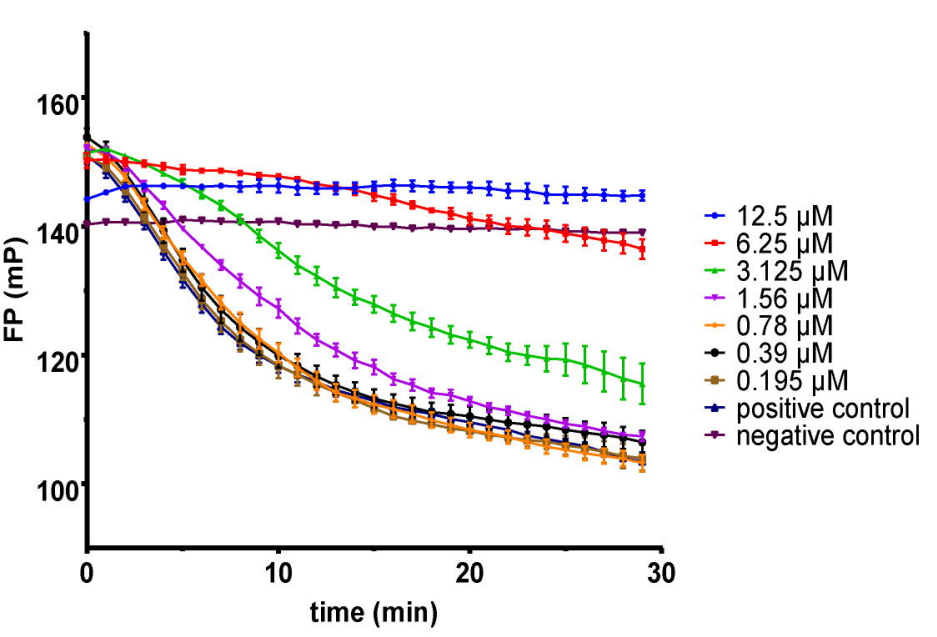

D)

$11(\mu \mathrm{M})$

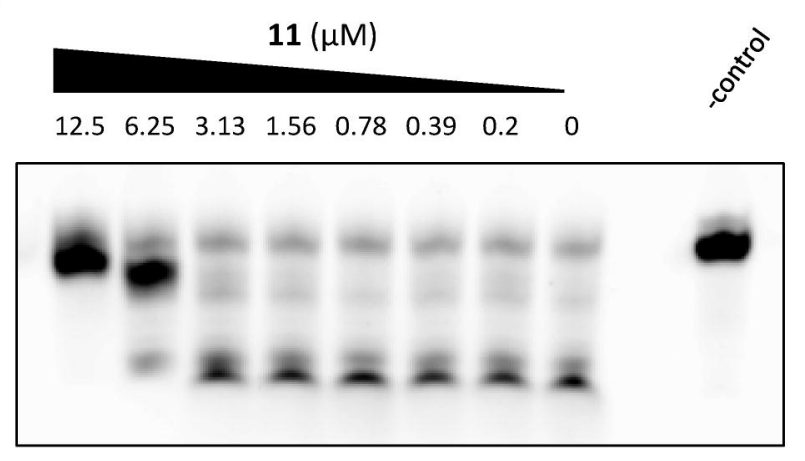

G)

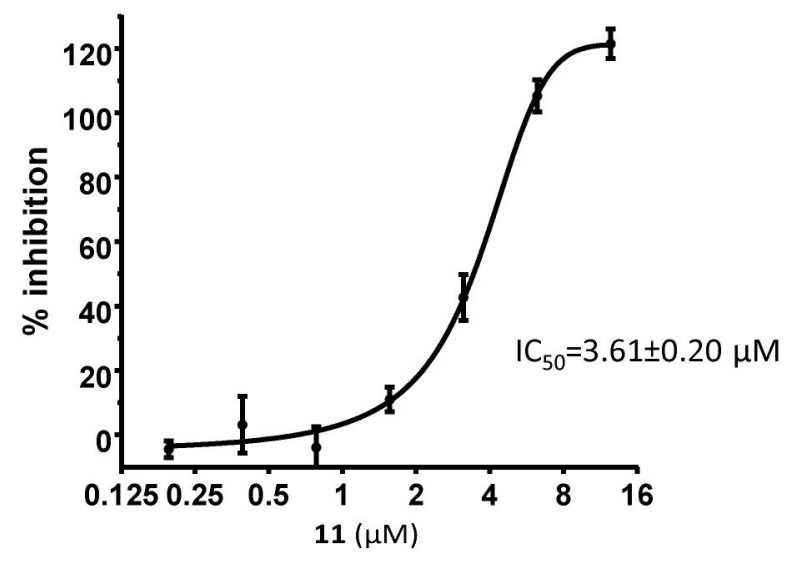

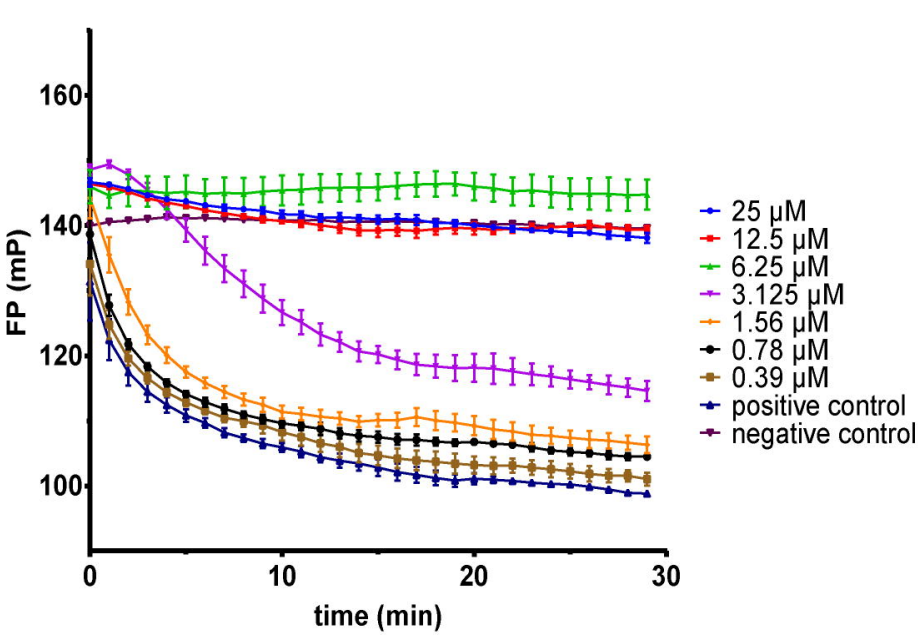

E)

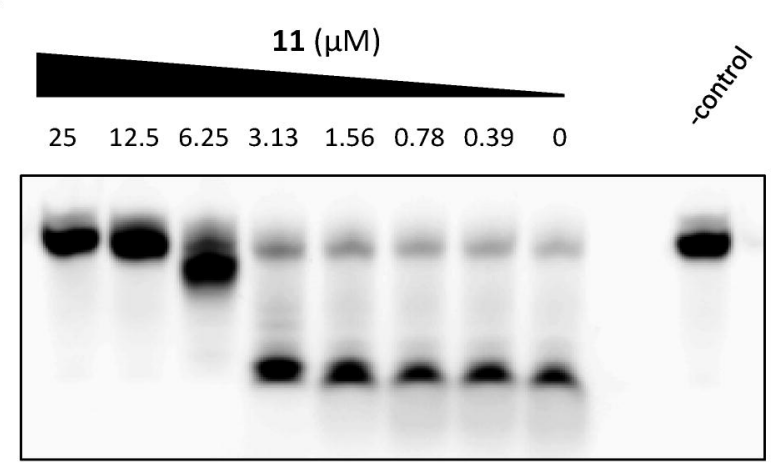

H)

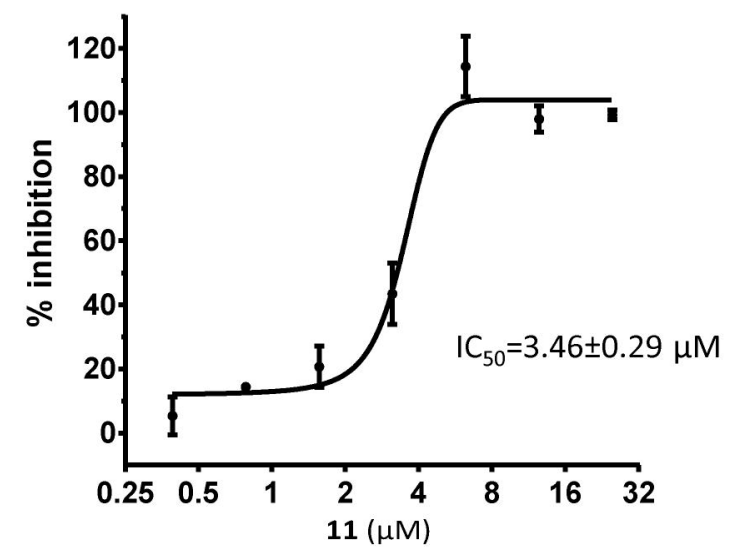

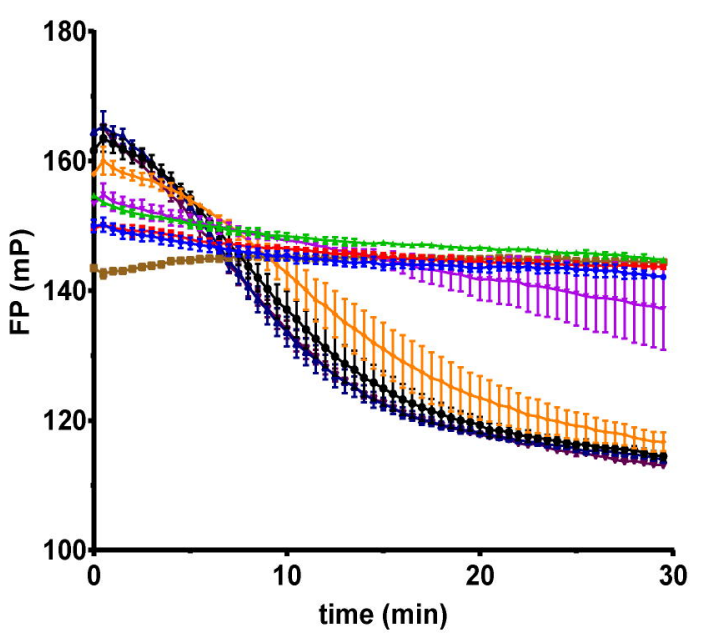

$-16 \mu \mathrm{M}$ $-8 \mu \mathrm{M}$ $-4 \mu \mathrm{M}$ $+1 \mu \mathrm{M}$ $-0.5 \mu \mathrm{M}$
$+0.25 \mu \mathrm{M}$

- positive control negalive control

F)

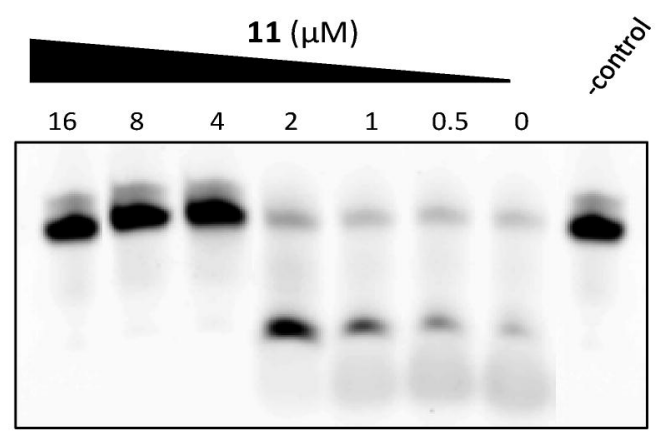

I)

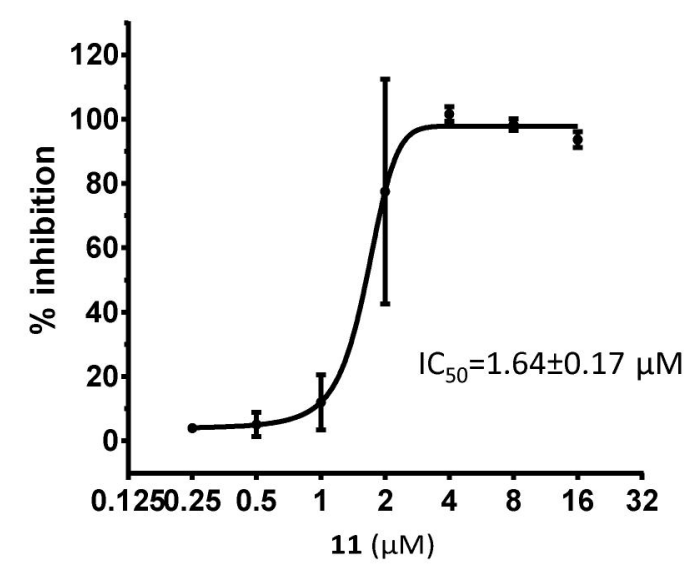

